\title{
GRUPO GINÁSTICO UNESP: \\ CONTRIBUIÇÕES DA "GINÁSTICA PARA TODOS" NA FORMAÇÃO DE SEUS PARTICIPANTES
}

\begin{tabular}{c} 
UNESP GYMNASTICS GROUP: \\
"GYMNASTICS FOR ALL" \\
CONTRIBUTIONS TO PARTICIPANTS TRAINING \\
GRUPO GIMNÁSTICO UNESP: \\
CONTRIBUCIONES DE LA "GIMNASIA PARA TODOS" \\
A LOS PARTICIPANTES DE SU FORMACIÓN \\
\hline
\end{tabular}

\author{
Marina Aggio Murbach ${ }^{1}$ \\ Paulo Roveri de Afonso ${ }^{1}$, \\ Letícia Bartholomeu de Queiroz Lima \\ Laurita Marconi Schiavon ${ }^{2}$
}

\begin{abstract}
RESUMO
A Ginástica Para Todos é uma prática corporal gímnica, essencialmente de caráter demonstrativo, que combina os fundamentos da ginástica com diferentes formas de expressão corporal. Dentro desta proposta surge, em 2011, o Grupo Ginástico Unesp como um projeto de extensão universitária do Departamento de Educação Física, Instituto de Biociências da Universidade Estadual Paulista/Campus Rio Claro - SP, coordenado pela Profa. Dra. Laurita Schiavon. Seu método de trabalho e de composição coreográfica baseia-se na proposta do Grupo Ginástico Unicamp, referência nesta prática corporal no Brasil. Com o objetivo de verificar as contribuições para a formação profissional dos integrantes do Grupo Ginástico UNESP (GG Unesp), a presente pesquisa qualitativa descritiva, utilizou-se de questionário e a análise foi desenvolvida por meio da técnica de análise de conteúdo (LAVILLE; DIONNE, 1999). Participaram da pesquisa 32 universitários, membros do GGUnesp de 2011 a 2013 e constatou-se que $87 \%$ dos participantes acreditam que o referido projeto contribuiu para a formação profissional dos mesmos e as categorias levantadas pelo estudo apontaram as contribuições ou não na formação dos integrantes, sendo: trabalho em equipe; fundamentos da ginástica; elaboração de coreografias; valores humanos; capacitação técnica; segurança no ensinamento dos exercícios; criatividade e aprofundamento das disciplinas da graduação.
\end{abstract}

PALAVRAS-CHAVE: Ginástica. Relações humanas. Valores. Formação profissional.

\begin{abstract}
Gymnastics for All is a gymnastics body practice, essentially demonstrative, that combines gymnastics foundations with different forms of body language. Within this proposal, in 2011, the Unesp Gymnastics Group arises as a university extension program of the Department of Physical education, Institute of Biosciences, State university of São Paulo/ Rio Claro - SP campus, coordinated by Professor Laurita Schiavon. Its working and choreographic composition method is based on the Unicamp Gymnastics Group proposal, reference in this body practice in Brazil. Aiming to verify the contributions to the vocational training of Unesp Gymnastics Group members (GG Unesp), the present descriptive qualitative research utilized a questionnaire and the data analysis
\end{abstract}

${ }^{1}$ Universidade Estadual de São Paulo - UNESP, Rio Claro, São Paulo - Brasil

${ }^{2}$ Universidade Estadual de Campinas - UNICAMP, Campinas, São Pulo - Brasil

Contato: paulo.roveri@hotmail.com

Submetido em: 15 abr. 2016 Aceito em: 15 jul. 2016

\begin{tabular}{|l|l|l|l|l|l|l}
\hline (C) Conexões & Campinas, SP & v. 14 & n. 3 & p. 71-88 & jul./set. 2016 & ISSN 1983-9030
\end{tabular}


was developed thought content analysis technique (LAVILLE; DIONNE, 1999). Participated in this research 32 university students members of GG Unesp from 2011 to 2013 and found that $87 \%$ of the participants believe that this project contributed to their vocational training. The raised categories by this research show the contributions or not contributions in their training, as: team work, gymnastics foundations, choreography elaboration, human values, technical capacitation, security in teaching exercises, creativity and deepening of undergraduate disciplines.

KEYWORDS: Gymnastic. Human relations. Value. Vocational training.

\section{RESUMEN}

La Gimnasia para Todos es uma práctica corporal gímnica, essencialmente de carácter demonstrativo, que combina los fundamentos de la gimnasia com diferentes formas de expresión corporal. Com esta propuesta surge, em 2011, el Grupo Gimnástico Uesp como proyecto de extensión universiaria del Departamento de Educación Física, de la Universidad Estatal Paulista/Campus Rio Claro - SP, coordenado por la Profa. Dra. Laurita Schiavon. Su método de trabajo y composición coreográfica se basa em la propuesta del Grupo Gimnástico Unicamp, referencia de esta práctica corporal em Brasil. Com el objetivo de verificar las contribuciones para la formación professional de los integrantes del Grupo Gimnástico Unesp, esta investigación cualitativa-descriptiva, utilizo um cuestionario que fue analizado por médio de la técnica de análisis de contenido (LAVILLE; DIONNE, 1999). Paticiparon em la investigación 32 universitários, membros del Grupo de 2011 a 2013 y se observo que $87 \%$ de los participantes creen que el referido proyecto contribuyó em su formación professional. Las categorias levantadas apuntaron las contribuciones o no em la formación de los integrantes, siendo: trabajo em equipo; fundamentos de la gimnasia; elaboración de coreografias; valores humanos; capacitación técnica; seguridade em la enseñanza de los ejercicios; creatividad y ampliación de las disciplinas de graduación.

PALABRAS CLAVE: Gimnasia. Ralaciones humanas. Valores. Formación professional. 


\title{
INTRODUÇÃO
}

Podemos encontrar na literatura diferentes definições sobre a conceituação de Ginástica para Todos (GPT). No âmbito internacional podemos citar a definição de GPT segundo a Federação Internacional de Ginástica ${ }^{1}$ que tem uma concepção de GPT que destaca características como, variedade de atividades adequadas para todas as pessoas, diversidade de faixa etária, habilidades e cultura, com um foco voltado para a saúde, bem-estar físico, social, intelectual e psicológico, e embasado em quatro pressupostos: Fun, Fitness, Fundamentals $e$ Friendship (Alegria, Aptidão, Fundamentos e Amizade) e pode envolver em suas apresentações, Ginástica com ou sem aparelhos e Ginástica e dança.

No cenário brasileiro podemos destacar a conceituação de Pérez Gallardo e Souza, ${ }^{2: 292}$ que acredita na valorização da formação humana e que conceitua a GPT como:

\begin{abstract}
Uma manifestação da cultura corporal, que reúne as diferentes interpretações da Ginástica (Natural, Construída, Artística, Rítmica Desportiva, Aeróbica, etc.) integrando-as com outras formas de expressão corporal (Dança, Folclore, Jogos, Teatro, Mímica, etc.), de forma livre e criativa, de acordo com as características do grupo social e contribuindo para o aumento da interação social entre os participantes.
\end{abstract}

Esse conceito foi desenvolvido a partir da experiência vivida por esses autores, Elizabeth Paoliello Machado de Souza e Jorge Pérez Gallardo que coordenaram o Grupo Ginástico Unicamp (GGU), um projeto de extensão universitária em Ginástica para Todos, desenvolvido na Faculdade de Educação Física (FEF) da Universidade Estadual de Campinas (Unicamp), iniciado em $1989^{3}$, contando com a participação de alunos da universidade, professores de Educação Física e profissionais de outras áreas.

Ancorada nos princípios: formação humana e capacitação, podemos destacar alguns pontos importantes, segundo Paoliello et al., ${ }^{3}$ que norteiam a proposta de Ginástica para Todos pelo GGU, são eles:

- O incentivo e a valorização do indivíduo em benefício do grupo;

${ }^{3}$ O Grupo Ginástico Unicamp foi criado pelas professoras Elizabeth Paoliello e Vilma Lení Nista-Piccolo. Posteriormente assumem a coordenação a Profa. Elizabeth e o Prof. Jorge Pérez Gallardo e atualmente os coordenadores são: Marco Antonio Coelho Bortoleto e Larissa Graner.

\begin{tabular}{|l|l|l|l|l|l|l}
\hline CC Conexões & Campinas, SP & v. 14 & n. 3 & p. 71-88 & jul./set. 2016 & ISSN 1983-9030
\end{tabular}


- O conteúdo utilizado parte das experiências individuais, socializadas a fim de servirem de base para a exploração de todo o grupo;

- A liberdade na utilização dos conteúdos da cultura corporal;

- O resgate dos valores culturais de cada grupo social.

- O prazer na atividade (ludicidade);

- A promoção da cooperação e da participação;

- A experimentação de diferentes formas de organização social;

- O estímulo à auto-superação e à criatividade;

- A possibilidade de participação de todos os membros da sociedade (criança, adultos, idosos, deficientes, etc...);

- A discussão crítica-superadora das diferentes manifestações da cultura corporal que sejam utilizadas;

- O aumento da interação social;

- A demonstração das composições como produto final do processo educativo;

- A elaboração e respeito às normas, regras e regulamentos criados pelo grupo.

O GGU realizou diversas apresentações, em eventos nacionais e internacionais, além de turnês pela Europa e Ásia, tornando-se referência dessa modalidade no Brasil, sendo responsável por diversas capacitações sobre essa prática corporal e gerando oportunidades de intercâmbio para seus participantes. Tem sido um espaço de formação para muitos alunos da Unicamp e de outras instituições. Consequentemente, muitos de seus integrantes e exintegrantes têm levado a Ginástica para Todos para as escolas, faculdades, e outras organizações, mantendo um panorama favorável para a difusão e discussão da cultura Ginástica, ${ }^{4}$ como é o caso do Grupo Ginástico UNESP.

O Grupo Ginástico Unesp (GG UNESP), criado em 2011, por uma ex-integrante do GGU e baseado nos mesmos pressupostos do referido grupo, sob orientação e coordenação das professoras Laurita Marconi Schiavon e Silvia Deustch, é um projeto de extensão universitária do Departamento de Educação Física, do Instituto de Biociências da Universidade Estadual Paulista/Campus Rio Claro - SP, com o objetivo de proporcionar aos universitários um espaço de vivências e de estudos em Ginástica para Todos. ${ }^{5}$ Como já 
mencionado, seu método de ensino baseia-se, segundo Schiavon, ${ }^{5}$ na proposta do Grupo Ginástico Unicamp, com quatro grandes eixos:

- Divulgar a Ginástica para Todos;

- Elaborar coreografias com exploração de temas e/ou materiais alternativos, auxiliado por um processo participativo, democrático e de formação de valores;

- Apresentar as coreografias em Festivais em nível regional, estadual, nacional e internacional;

- Gerar trabalhos científicos a partir das experiências vividas e questionamentos surgidos no projeto de extensão universitária (trabalhos de conclusão de curso, iniciação científica, apresentações em congressos).

Ademais, como um projeto de extensão seu objetivo vai além dos muitos já apresentados acima, pois, de acordo com Freire ${ }^{6}$ a extensão com um enfoque educativo, faz com que professores e alunos assumam um papel de sujeitos de seu aprendizado, mediadores do objetivo que desejam. Assim, o objetivo desta pesquisa foi verificar as contribuições para a formação profissional dos integrantes do Grupo Ginástico UNESP, por meio de uma análise qualitativa realizada por meio de questionário.

\section{MÉTODO}

A abordagem metodológica adotada para esta pesquisa qualitativa será de caráter descritivo, com dados qualitativos, coletados por meio de questionário composto por questões abertas pertinentes à temática da pesquisa. O questionário foi submetido e aceito pelo Comitê de Ética e Pesquisa (CEP) da Universidade Estadual Paulista - UNESP- Rio Claro (Parecer: 742.098). Participou dessa pesquisa um total de 32 sujeitos que se enquadraram nos seguintes critérios de seleção: universitários participantes do Grupo Ginástico UNESP até 2013, com mínimo de um ano de participação e duas apresentações com o Grupo e que assinaram o Termo de consentimento livre e esclarecido. Os dados qualitativos foram analisados pela técnica de análise de conteúdo proposta por Laville e Dionne. ${ }^{7} \mathrm{O}$ princípio da análise de conteúdo está relacionado com a etapa do recorte dos conteúdos, a definição das categorias analíticas e a categorização final das unidades de análise. ${ }^{7}$ 


\section{RESULTADOS E DISCUSSÃO}

O presente estudo tinha como proposta inicial um total de 79 possíveis participantes, porém para assegurar os critérios de seleção dos sujeitos a amostra foi reduzida, como pode ocorrer em pesquisas com aplicação de questionários, e tivemos o retorno de 32 participantes, que serão apresentados, a seguir, de acordo com o ano de ingresso no Grupo Ginástico Unesp (TABELA 1).

Tabela 1 - Enquadramento dos participantes da pesquisa de acordo com seu ano de ingresso no Grupo

\begin{tabular}{lccc}
\hline Ano de ingresso no grupo & $\mathbf{2 0 1 1}$ & $\mathbf{2 0 1 2}$ & $\mathbf{2 0 1 3}$ \\
\hline Total de participantes & 18 & 33 & 28 \\
Ingressantes & 18 & 20 & 10 \\
Participantes da pesquisa* & 17 & 19 & 7 \\
Responderam & 13 & 14 & 5 \\
Não responderam & 4 & 5 & 2 \\
\hline Legenda: Total de participantes que estão dentro dos critérios da seleção dos sujeitos da pesquisa.
\end{tabular}

$\mathrm{Na}$ Tabela 1 foram apresentados os participantes de acordo com seu ano de ingresso, desconsiderando os integrantes que ficaram menos de um ano no grupo. No ano de 2011, dos 18 indivíduos participante 17 foram classificados de acordo com os critérios, 13 responderam os questionários, ficando 4 indivíduos sem responder. No ano de 2012 o Grupo teve a participação de 33 alunos, dos 20 ingressantes, 19 foram classificados dentro dos critérios, 14 responderam e 5 não responderam. Em 2013 o Grupo contou com a participação de 28 integrantes, dos 10 novos, 7 foram classificados dentro dos critérios, 5 responderam e 2 não responderam. Sendo assim o presente estudo contou com a participação de $74 \%$ de seus integrantes.

\section{ASPIRAÇÕES DOS PARTICIPANTES AO INGRESSAR NO GG UNESP}

Sendo a Ginástica para Todos uma prática corporal que não se encontrava presente no universo da Unesp/Rio Claro, foi questionado aos integrantes quais razões eles levaram em consideração quando decidiram participar do projeto de extensão universitária. 
Tabela 2 - Aspirações em relação a participação no Grupo Ginástico UNESP

\begin{tabular}{lcc}
\hline Critérios & Frequência Absoluta & Frequência Relativa $^{4}$ \\
\hline Conhecer o projeto - práticas ginásticas & 18 & $56,2 \%$ \\
Interação social & 9 & $28,1 \%$ \\
Manutenção de uma modalidade & 4 & $12,5 \%$ \\
Condicionamento físico & 9 & $28,1 \%$ \\
Aumento do repertório motor & 7 & $21,9 \%$ \\
Prazer/Gosto pela ginástica & 10 & $31,2 \%$ \\
Ex-praticante de ginástica & 5 & $15,6 \%$ \\
Capacitação profissional & 7 & $21,9 \%$ \\
Ausência de mecanismo de seleção & 2 & $6,2 \%$ \\
Outros & 4 & $12,5 \%$ \\
\hline
\end{tabular}

Podemos observar uma variedade de critérios que os participantes levaram em consideração quando buscaram pela prática da GPT. A categoria com maior frequência relativa, mais de $56 \%$ das respostas, foi o "conhecer o projeto - práticas ginásticas", a grande maioria relatou o interesse de conhecer essa "nova" prática corporal que estava sendo proposta como projeto de extensão, porém foram encontradas algumas respostas interessantes, como é o caso do participante P13 que relata: “Como nunca havia tido contato com a ginástica na escola, ao me deparar com este projeto de ginástica para universitários, tive a oportunidade de conhecer e praticar uma ginástica dentro da minha realidade, diferente da ideia de ginástica de alto rendimento que a mídia apresenta", reforçando um triste cenário do nosso sistema de ensino.

Outro participante relata seu interesse após ver a apresentação do GGU, P18: "Entrei para o grupo pela curiosidade de conhecer esse universo da Ginástica Geral, após ver alguns vídeos de apresentações do grupo de Ginástica Geral da Unicamp mostrado pela professora Laurita, ocorreu o convite para participar do grupo que ela ia começar na universidade, fui nas primeiras aulas e nunca mais sai”.

Na categorização encontramos o "prazer/gosto pela Ginástica", teve mais de 31\% de citação, nesse agrupamento foram apresentados, o interesse pela Ginástica, a admiração, o gosto e o prazer de pratica-la, como podemos observar nas respostas de P12: "Sempre tive vontade de praticar ginástica, mas na minha cidade não tinha, aí quando vim para a faculdade não

${ }^{4}$ Era possível escrever vários critérios. 
perdi a oportunidade" e P3: "Por ser a ginástica artística uma modalidade que sempre quis praticar, busquei um projeto que a abrangesse e que se adequasse com o nível de ginástica $[\ldots] "$.

No critério "interação social" a amizade foi um fator apontando nas respostas, alguns foram convidados por seus amigos que já participavam do Grupo e outros foram participar por ser um projeto que envolve um grande número de participantes, como foi o caso de P20: "[...] conviver mais com os meus amigos e fazer novos" e de P31: "Sempre gostei de praticar exercícios físicos e principalmente envolvendo grupos de pessoas".

Sendo na atualidade a Ginástica fortemente vinculada ao condicionamento físico, um critério que teve mais de $28 \%$ foi o "condicionamento físico", onde os participantes relatam a necessidade de praticar uma atividade física e melhorar seu condicionamento, como podemos observar na resposta de P25: "[...] buscar uma melhora no condicionamento físico, alongamento e flexibilidade". Outro item também citado pelos praticantes foi "aumento do repertório motor", com mais de $21 \%$, no qual os indivíduos relatavam a vontade aprender movimentos novos, desenvolvendo assim novas habilidades motoras.

Dentro da "capacitação profissional", mais de $21 \%$ dos participantes entraram no Grupo com o interesse de se aperfeiçoar como profissional, como nas respostas encontradas de P13: "[...] me proporcionaram apresentações e o conhecimento da modalidade, principalmente para difundir a prática em outros locais como escola ou clubes que não possuem um material especifico para prática dos diversos tipos de ginástica”; e de P16: "[...] as experiências com fundamentos básicos da ginástica, o que pode me propiciar experiência com o conteúdo para a minha futura atuação docente”; e de P27: “[...] aprender mais sobre as diferentes modalidades de ginástica e me especializar para futuramente trabalhar na área acadêmica com esse tema".

Dos critérios encontrados, foi classificado o grupo dos “ex-praticantes de Ginástica", com $15 \%$ das repostas, onde são destacados, participantes que tiveram um grande período destinado a treinos e competições e quando entraram na universidade sentiram a vontade de praticar novamente, como o caso de P28: “Comecei a praticar a ginástica quando pequena e me apaixonei pelas diferentes modalidades. Fiz 8 anos de ginástica olímpica, como era

\begin{tabular}{l|l|l|l|l|l|l}
\hline (C) Conexões & Campinas, SP & v. 14 & n. 3 & p. 71-88 & jul./set. 2016 & ISSN 1983-9030 \\
\hline
\end{tabular}


chamada, durante meu ensino fundamental. Meu treinamento era composto por ginástica artística, rítmica, acrobática e de trampolim [...]". Na "manutenção de uma modalidade aprendida" foram classificadas por indivíduos que tiveram experiências anteriores com alguma modalidade, como é apresentando por P19: “[...] foi a maneira de eu aproveitar o que já sabia e aprender mais sobre”.

Um critério apresentado foi a "ausência de mecanismos de seleção" um dado importante, pois a GPT é uma prática corporal, que oportuniza a prática de Ginástica para qualquer pessoa, independentemente de suas limitações. ${ }^{8}$ E o Grupo Ginástico Unesp tem em sua concepção a ausência de mecanismo de seleção, dando a oportunidade de qualquer universitário participar. Isso é relatado pelo participante P16: “[...] a ausência de mecanismo de seleção, o que favorece minha participação, uma vez que não sou especialista em nenhuma modalidade de ginástica $[\ldots]$ ”.

Houve a necessidade de agrupar uma categoria denominada "outros", pois foram apresentados alguns critérios individuais, porém de grande importância para o Grupo, como o depoimento de P23: “[...] motivação proporcionada pela disciplina de Ginástica Artística no semestre anterior"; de P16: "a perspectiva lúdica explorada nas atividades; os momentos de criação e expressão, onde podemos trabalhar e aperfeiçoar; a oportunidade de apresentar em eventos sem fins competitivos, apenas com intuito de compartilhar experiências com outras pessoas; exploração de materiais e composições coreográficas [...]”.

\section{CONTRIBUIÇÕES DO GRUPO GINÁSTICO UNESP}

A seguir, serão apresentados os resultados obtidos no questionamento sobre a contribuição da participação no grupo na formação profissional de seus participantes.

Tabela 3 - Contribuição do Grupo Ginástico UNESP na formação de seus integrantes

\begin{tabular}{lcc}
\hline & Participantes & Porcentagem \% \\
\hline Não contribuiu & 1 & $3,12 \%$ \\
Pouco contribuiu & 3 & $9,37 \%$ \\
Contribuiu de forma satisfatória & 11 & $34,37 \%$ \\
Contribuiu significativamente & 17 & $53,12 \%$ \\
\hline Total & 32 & $100 \%$ \\
\hline
\end{tabular}


Observando a Tabela 3 podemos ver que mais da metade dos participantes $(53,12 \%)$ acreditam na contribuição significativa do Grupo na sua formação profissional, dos 32 participantes da pesquisa, mais de $87 \%$ deles disseram que o grupo contribuiu de forma satisfatória e significativa, se considerar a "pouca contribuição" esse número vai para 96,9\% do total de participantes da pesquisa.

$\mathrm{Na}$ tentativa de melhor compreender essa contribuição, será apresentado, a seguir, a transcrição das respostas, de acordo com a categorização dos resultados, que vão ilustrar esse cenário que foi encontrado na pesquisa. Serão apresentadas as categorias:

- Trabalho em equipe;

- Fundamentos da ginástica;

- Criação de coreografias;

- Valores humanos;

- Técnicas de movimentos ginásticos;

- Segurança no ensinamento dos exercícios;

- Criatividade;

- Aprofundamento das disciplinas da graduação;

- Não contribuiu.

Quadro 1- Contribuição para o trabalho em grupo

\begin{tabular}{|c|c|}
\hline & Trabalho em grupo \\
\hline p3 & $\begin{array}{l}\text { [...] O projeto também me deu a capacidade ainda maior de lidar com um grupo composto por } \\
\text { pessoas (tão distintas, no caso) }\end{array}$ \\
\hline $\begin{array}{l}\text { p4 e } \\
\text { p19 }\end{array}$ & {$[\ldots]$ trabalho em equipe $[\ldots]$} \\
\hline p5 & Aprender a trabalhar em equipe $[\ldots]$ \\
\hline p6 & Aprendi a trabalhar em grupo $[\ldots]$ \\
\hline p7 & Pois ajuda no âmbito da cooperação [...] \\
\hline p8 & [...] como lidar com equipe. \\
\hline p10 & {$[\ldots]$ trabalho em grupo $[\ldots]$} \\
\hline p11 & melhor relação em trabalhos em equipe, comprometimento [...] \\
\hline p18 & $\begin{array}{l}\text { O projeto auxilia no processo de formação, pois nele realizamos diversas atividades que } \\
\text { necessitam do trabalho coletivo [...] }\end{array}$ \\
\hline p22 & {$[\ldots]$ também contribuiu muito para a as questões de trabalho em equipe $[\ldots]$} \\
\hline p25 & $\begin{array}{l}\text { Por ser bióloga, acredito que a participação no grupo, para mim, não contribuiu tanto como para } \\
\text { os educadores físicos. Mas com certeza me ajudou a melhorar o trabalho em grupo, resolução de } \\
\text { problemas. }\end{array}$ \\
\hline p30 & [..] E também conviver em grupo [...] \\
\hline p28 & [...] importância do trabalho em equipe. \\
\hline
\end{tabular}


Segundo Souza ${ }^{8: 91}$ o aumento da interação social e vivências motoras podem ser desenvolvidos em quatro momentos:

[...] o aumento do Desenvolvimento e aperfeiçoamento das habilidades individuais, a fim de aumentar os recursos a serem socializados, selecionando os movimentos conhecidos pela maioria e que permitem atingir o que chamamos de criação de uma linguagem comum de movimentos; [...] Intercâmbio de experiências entre os alunos, onde são utilizadas diferentes formas de organização grupal. Inicia-se aos pares, passando a seguir para trios, quartetos, grupos de oito, até um grande grupo que, de acordo com a idade e experiência dos alunos, pode chegar a 10, 12, 15 ou mais integrantes; [...] Alcançada a estrutura grupal, exploramos diversas formas coreográficas, tais como: formações em linhas retas, curvas e combinadas; formações em círculos, triângulos, quadrados, etc.; [...] Utilização das experiências motoras individuais e coletivas dentro das formas coreográficas descobertas.

A participação em um grupo de Ginástica para Todos auxilia os jovens a terem uma maior experiência em trabalhos coletivos, pois a aula é articulada para que ocorra um aumento da interação social e vivências humanas, onde cada pessoa ou grupo de pessoas exercem a função de mediador em determinadas atividades. As dinâmicas trabalham a participação coletiva na construção e execuções de movimentos, coreografias, exercícios entre outros.

Um dado importante para ser ressaltado, como foi apresentado anteriormente, o grupo tem a participação de alunos de outros cursos da universidade, podendo favorecer assim algumas opiniões interessantes de serem observadas, como é o caso de P25 “Por ser bióloga, acredito que a participação no grupo, para mim, não contribuiu tanto como para os educadores físicos. Mas com certeza me ajudou a melhorar o trabalho em grupo, resolução de problemas". 
Quadro 2 - Contribuições para os fundamentos da ginástica

\begin{tabular}{|c|c|}
\hline & Fundamentos da ginástica \\
\hline p2 & O Grupo Ginástico Unesp abriu minha visão para um campo de exercícios, fundamentos [...] \\
\hline p3 & $\begin{array}{l}\text { A ginástica sempre foi interessante para mim, porém desconhecia. Através do projeto, tomei } \\
\text { conhecimento de tal modalidade e passei a admirá-la ainda mais! [...] }\end{array}$ \\
\hline p4 & Aprendi bastante sobre ginástica [...] \\
\hline p8 & Aprendizagem da ginástica de uma forma mais ampla [...] \\
\hline p10 & Novas aprendizagens na ginástica $[\ldots]$ \\
\hline p13 & $\begin{array}{l}\text { Foi importante a pratica da ginástica geral pra um futuro em que necessite ensinar esse tipo de } \\
\text { pratica e principalmente para desmistificar a ginástica como uma pratica perfeccionista e possível } \\
\text { apenas para poucas pessoas, além de eu poder conscientizar outros destes aprendizado. }\end{array}$ \\
\hline p16 & $\begin{array}{l}\text { Acredito que contribui para o meu processo de formação com conhecimentos relativos à ginástica, } \\
\text { mas também com metodologia de ensino diversos que podem ser transpostas para outros conteúdos } \\
{[\ldots . .]}\end{array}$ \\
\hline p18 & $\begin{array}{l}\text { [...] melhor compreensão das possibilidades da Ginástica, auxiliando assim nossa futura atuação } \\
\text { docente. }\end{array}$ \\
\hline p19 & [...] além de conhecimentos sobre os fundamentos da ginástica geral. \\
\hline p21 & Saber o mínimo sobre ginástica geral, qual seu objetivo, como por der trabalhada e explorada. \\
\hline p23 & $\begin{array}{l}\text { Auxiliou na compreensão de novas formas de práticas físicas e corporais. Expandi minha concepção } \\
\text { de que tais práticas estavam quase que exclusivamente ligadas à saúde ou alto rendimento. }\end{array}$ \\
\hline p24 & $\begin{array}{l}\text { A ginástica é uma prática muito diversificada e oferece diversas possibilidades, o contato com o GG } \\
\text { me mostrou algumas delas, e como é possível que todos pratiquem ginástica. }\end{array}$ \\
\hline p28 & $\begin{array}{l}\text { Participar do Grupo Ginástico foi uma experiência muito positiva, pois foi nesse projeto que aprendi } \\
\text { sobre a modalidade ginástica geral[...] }\end{array}$ \\
\hline
\end{tabular}

A busca pelo conhecimento é um caminho que muitos jovens seguem, na universidade podemos encontrar a possibilidade de conhecer diferentes conteúdos realizando as práticas corporais oferecidas, como: danças, lutas, esportes e a ginástica. Sendo assim, muitos jovens participam de grupos universitários para adquirir tais conhecimentos. Além dos conhecimentos decorrentes das atividades e dinâmicas realizadas nos encontros, a participação no Grupo Ginástico Unesp oferece aos seus participantes a oportunidade de participar de eventos científicos no âmbito da Ginástica para Todos, favorecendo assim uma maior aprendizagem dessa prática corporal.

Quadro 3 - Contribuições para criação de coreografias

\begin{tabular}{ll}
\hline & Criação de coreografia \\
\hline p17 & {$[\ldots]$ Além de ter tido a experiência de ajudar na criação de uma coreografia de ginastica geral $[\ldots]$} \\
p10 & {$[\ldots]$ criação de coreografia $[\ldots]$} \\
p19 & {$[\ldots]$ montagem de coreografia $[\ldots]$} \\
p26 & {$[\ldots]$ experienciei determinadas situações de montagem de coreografia $[\ldots]$} \\
p28 & {$[\ldots]$ na criação de coreografias $[\ldots]$} \\
p29 & Me auxiliou no aprendizado de organização de coreografias $[\ldots]$ \\
\hline
\end{tabular}


Sendo, um dos objetivos finais da Ginástica para Todos; a criação e apresentações de coreografias, essa ferramenta pode ser de suma importância para futuros professores de Educação Física, visando que o mesmo é frequentemente requisitado para elaboração de coreografias em datas festivas nas escolas, na elaboração de novas coreografias de danças em clubes, academias, etc. Nesse caso a experiência torna-se mais interessante pois o processo criativo desenvolvido pelo Grupo Ginástico Unesp, que se embasa teoricamente na proposta desenvolvida no Grupo Ginástico Unicamp, valoriza o processo criativo coletivo, mediado pelo professor e aberto para que seja composto com as ideias dos participantes e não por um coreógrafo que traz uma ideia pronta. As ideias de todos podem ser valorizadas e aproveitadas nas composições, pois a criatividade é tão valorizada quanto uma habilidade ginástica.

Quadro 4 - Contribuição para valores humanos

\begin{tabular}{|l|l|}
\hline & Valores humanos \\
\hline p5 & {$[\ldots]$ respeitar ideias diferentes $[\ldots]$} \\
\hline p6 & {$[\ldots]$ lidar com as diferenças $[\ldots]$} \\
\hline p7 & {$[\ldots]$ liderança durante os ensaios $[\ldots]$} \\
\hline p11 & {$[\ldots]$ respeitar as diferentes $[\ldots]$} \\
\hline p19 & Acredito que foi de grande importância, pois auxilia no respeito com o próximo $[\ldots]$ \\
\hline p30 & {$[\ldots]$ sabendo respeitar ao próximo. } \\
\hline
\end{tabular}

Outro aspecto importante ressaltado pelos participantes foi a contribuição da GPT na formação de valores humanos, que segundo Souza ${ }^{8: 86}$ o professor deve criar " [....] atividades onde o aluno tenha a oportunidade de experienciar a cooperação, a responsabilidade, a amizade, a solidariedade, o respeito a si próprio e aos demais, etc".

Quadro 5 - Contribuições para conhecimento das técnicas dos movimentos ginásticos

\begin{tabular}{ll}
\hline & Técnicas dos movimentos ginásticos \\
\hline p1 & $\begin{array}{l}\text { Visando trabalhar com as artes, o projeto proporciona vivências e experiências de atividades, } \\
\text { exercícios, movimentos (como fazer e ensinar) que com certeza utilizarei }\end{array}$ \\
p26 & Participando do Grupo Ginástico Unesp aprendi algumas habilidades ginásticas importantes, [...] \\
p28 & [...] Junto com ele tive experiências em relação à técnica de movimento [...] \\
p30 & $\begin{array}{l}\text { O projeto contribui para a formação profissional através de técnicas e movimentos aprendidos } \\
\text { durante minha participação [...] }\end{array}$ \\
\hline
\end{tabular}

Dentre as contribuições citadas, relacionadas ao trabalho em equipe, conhecimento sobre ginástica e valores humanos, foi possível observar também a contribuição para alguns

\begin{tabular}{|l|l|l|l|l|l|l}
\hline (C) Conexões & Campinas, SP & v. 14 & n. 3 & p. 71-88 & jul./set. 2016 & ISSN 1983-9030
\end{tabular}


participantes relacionada à execução de técnicas de movimentos ginástico, facilitando assim futuros ensinamentos dentro dessa proposta. Ainda relacionado as técnicas de movimentos, alguns participantes relataram a importância da aprendizagem da segurança na execução dos movimentos e no ensinamento dos movimentos, podendo ser observado nas transcrições a baixo.

Quadro 6 - Contribuições para segurança no ensinamento de exercícios

\begin{tabular}{ll}
\hline & Segurança no ensinamento de exercícios \\
\hline p4 & {$[\ldots]$ como confiar e assegurar outras pessoas } \\
p5 & {$[\ldots]$ segurança nos aparelhos de GA } \\
p17 & $\begin{array}{l}{[\ldots] \text { auxiliar os outros em atividades acrobáticas, fazendo segurança, dando dicas, entre outras }} \\
\text { coisas }\end{array}$ \\
\hline
\end{tabular}

Outra contribuição que foi encontrada foi relacionada ao repertório de atividades ginásticas que podem facilitar na elaboração de futuras aulas de ginásticas ou educação física escolar.

Quadro 7 - Contribuições para repertório de atividades ginásticas

\begin{tabular}{ll}
\hline & Repertório de atividades ginásticas \\
\hline p2 & $\begin{array}{l}{[\ldots] \text { ajuda a ter um repertório de atividade muito maior do que eu teria se não fizesse parte do }} \\
\text { mesmo }\end{array}$ \\
p5 & {$[\ldots]$ brincadeiras para realizar com as crianças nas aulas de ginástica $[. .]$.} \\
p20 & $\begin{array}{l}\text { Na questão do condicionamento físico, os alongamentos e as partes práticas, ou seja, tudo. Isso me } \\
\text { auxiliou na organização das minhas aulas tanto com idosos como com crianças }\end{array}$ \\
\hline
\end{tabular}

No Grupo Ginástico Unesp as aulas, quase sempre, iniciavam com brincadeiras, jogos lúdicos, como forma de aquecimento, visando sempre uma integração entre os participantes e participação de todos, ratificando o princípio de interação social entre os participantes. ${ }^{3}$

Quadro 8 - Contribuições no aprofundamento das disciplinas da graduação

\begin{tabular}{ll}
\hline Aprofundamento das disciplinas da graduação \\
\hline p12 & $\begin{array}{l}\text { Funciona como um aprofundamento da matéria que já temos na graduação, pois vivenciei mais } \\
\text { movimentos coreográficos e pude praticar mais. Assim acho que tenho mais noção de uma aula de } \\
\text { ginástica e mais ideias. }\end{array}$ \\
p14 & $\begin{array}{l}\text { Acredito que tudo que aprendi nas disciplinas de ginástica e atividades rítmicas entre outras, foram } \\
\text { aplicadas e aperfeiçoadas no grupo. }\end{array}$ \\
\hline
\end{tabular}

Na grade curricular do curso de Educação Física da Unesp Rio Claro existem as disciplinas de Ginástica I, II, e Ginástica Artística, e alguns participantes relataram que a participação no Grupo Ginástico favoreceu o aprofundamento dessas disciplinas, possibilitando uma maior

\begin{tabular}{l|l|l|l|l|l|l}
\hline (C) Conexões & Campinas, SP & v. 14 & n. 3 & p. 71-88 & jul./set. 2016 & ISSN 1983-9030
\end{tabular}


vivência com movimentos coreográficos, e habilidades ginásticas, reforçando o importante papel da extensão universitária para a formação dos estudantes e futuros profissionais. Assim, como já mencionado, a extensão torna-se eficaz à medida que também abrange os outros dois pilares da universidade, pesquisa e ensino, possibilitando ao graduando a oportunidade de interagir e constituir como futuro profissional de modo indissociável. ${ }^{9}$

\section{Quadro 9 - Contribuições para criatividade}

\begin{tabular}{ll}
\hline & Criatividade \\
\hline p15 & $\begin{array}{l}\text { A troca de experiência do grupo é enorme, temos pessoas que vieram de diversas áreas, o que fez } \\
\text { com que as aulas tivessem sempre algo novo e me ajuda em vários aspectos do futuro } \\
\text { profissional, sobretudo a criatividade. }\end{array}$ \\
p18 & {$[\ldots]$ da criatividade [...] }
\end{tabular}

Tendo entre as propostas desse trabalho de Ginástica para Todos atividades como: exploração de materiais de diferentes tipos e não apenas esportivos ou ginásticos, criação de movimentos coreográficos e trocas de experiências, foi possível encontrar nas transcrições das respostas a contribuição para a criatividades de seus participantes, algo bastante nítido ao assistir as coreografias de grupos que trabalham em proposta semelhante, que valorizam a criação coletiva, permeada por propostas lúdicas e criativas.

Na pesquisa foram encontradas duas repostas que consideraram que a participação no projeto não contribuiu para a formação profissional desses estudantes, sendo um do curso de Educação Física e outro de Ciências Biológicas.

Entre as diferentes contribuições apontadas pelos sujeitos da presente pesquisa, cinco delas relacionam-se diretamente com conteúdos específicos do curso de Educação Física e mais especificamente com conteúdos ginásticos: fundamentos da ginástica, elaboração de coreografias, capacitação técnica, segurança no ensinamento dos exercícios e aprofundamento das disciplinas da graduação. Porém três aspectos levantados tratam de questões mais amplas e que podem contribuir para a formação humana dos participantes, são eles: trabalho em equipe, valores humanos e criatividade. Essa é uma importante discussão, pois os projetos de extensão podem transcender o ensino específico de habilidades para estudantes ou para a comunidade e ensinar mais do que Ginástica, nesse caso, assim como 
nos alerta Freire, ${ }^{10}$ que devemos ensinar Esporte a todos, ensinar bem esporte a todos, ensinar mais do Esporte a todos e ensinar a gostar de Esporte.

\section{CONSIDERAÇÕES FINAIS}

Este trabalho propôs compreender quais foram as possíveis contribuições na formação profissional de praticantes da Ginástica para Todos, a partir da visão dos participantes do Grupo Ginástico Unesp e da proposta desenvolvida no Grupo Ginástico Unicamp. ${ }^{8}$

O objetivo do estudo foi alcançado, sendo apresentado que $87,4 \%$ dos participantes acreditam que a participação no Grupo Ginástico Unesp contribuiu em sua formação profissional, mais especificamente em relação ao trabalho em grupo, fundamentos da ginástica, criatividade, valores humanos, segurança e técnicas de movimentos.

Como todo estudo de caso, o trabalho apresenta limitações, não podendo ser generalizado, porém se faz necessário e importante para um registro e reconhecimento desse projeto no Departamento de Educação Física da Unesp-Rio Claro, assim como dar ênfase na valorização de projetos de extensão universitária, muitas vezes considerados de menor valor nas universidades.

Logicamente é importante considerar as muitas contribuições desse tipo de projeto e que acontecem porque ele traz um diferencial importante entre outros projetos de extensão, pois proporciona uma relação direta dos três importantes pilares da universidade, tendo pesquisas que embasam o desenvolvimento e a metodologia de ensino do projeto, que estimulam a produção de outras pesquisas como essa que teve início em uma iniciação científica (com bolsa CNPq), que oferece relações e complementações de ensino aos estudantes e que oferece à comunidade um retorno das produções da universidade.

Sendo a Ginástica para Todos, uma manifestação da cultura corporal que pode ser prazerosa, inclusiva e favorecer uma gama de benefícios aos seus participantes, seu estudo deveria ser ampliado, possibilitando assim um melhor entendimento dessa prática em outros grupos que trabalham com propostas semelhantes. 


\section{REFERÊNCIAS}

${ }^{1}$ FÉDÉRATION INTERNATIONALE DE GYMNASTIQUE (FIG). Gymnastics for all committee, regulations manual, 2009. Disponível em: <https://www.figgymnastics.com/site/page/view?id=474>. Acesso em: 05 de mar. 2014.

${ }^{2}$ PÉREZ GALLARDO, Jorge Sergio; SOUZA, Elizabeth Paoliello Machado de. A proposta de ginástica geral do Grupo Ginástico Unicamp. In: ENCONTRO DE GINÁSTICA GERAL, Campinas. Coletânea... Campinas: Gráfica Central da Unicamp, 1997. p. 25-32.

${ }^{3}$ PAOLIELLO, Elizabeth et al. Grupo Ginástico Unicamp: 25 anos. Campinas: Ed. da Unicamp, 2014.

${ }^{4}$ LACERDA, D. J.; BORTOLETO, Marco Antônio Coelho; PAOLIELLO Elizabeth. Grupo Ginástico Unicamp: 22 anos de ginástica geral. Conexões: revista da Faculdade de Educação Física da UNICAMP, Campinas, v. 10, n. esp., p. 192-208, dez. 2012.

${ }^{5}$ SCHIAVON, Laurita Marconi. Grupo Ginástico Unesp. 2010. Instituto de Biociências. Universidade Estadual Paulista "Júlio de Mesquita Filho", Rio Claro - SP. Disponível em: < http://proex-unesp.com.br>. Acesso em: 09 jan. 2014

${ }^{6}$ FREIRE, Paulo. Extensão ou comunicação? 5. ed. Rio de Janeiro: Paz e Terra, 1980.

${ }^{7}$ LAVILlE, Christian; DIONNE, Jean. A construção do saber: manual de metodologia da pesquisa em ciências humanas. Porto Alegre: Artmed, 1999.

${ }^{8}$ SOUZA, Elizabeth Paoliello Machado de. Ginástica geral: uma área do conhecimento da educação física. 1997. 163 f. Tese (Doutorado) - Universidade Estadual de Campinas. Faculdade de Educação Física, Campinas, SP, 1997. Disponível em: <http://cutter.unicamp.br/document/?code=vtls000114740>. Acesso em: 05 dez. 2013.

${ }^{9}$ MOITA, Filomena Maria Gonçalves da Silva Cordeiro; ANDRADE, Fernando Cézar Bezerra de. Ensino-pesquisa-extensão: um exercício de indissociabilidade na pós- 
graduação. Revista Brasileira de Educação, Rio de Janeiro, v. 14, n. 41, p. 269-393, maio 2009.

${ }^{10}$ FREIRE, João Batista. Pedagogia do futebol. Campinas: Autores Associados, 2003. 